Canadian

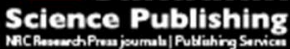

Applied Physiology, Nutrition, and Metabolism Physiologie appliquée, nutrition et métabolisme

\title{
Independent associations of polymorphisms in vitamin D binding protein (GC) and vitamin D receptor (VDR) genes with obesity and plasma 250 HD3 levels demonstrate sex dimorphism
}

\begin{tabular}{|r|l|}
\hline Journal: & Applied Physiology, Nutrition, and Metabolism \\
\hline Manuscript ID & apnm-2015-0284.R2 \\
\hline Danuscript Type: & Article \\
\hline Complete List of Authors: & $\begin{array}{l}\text { Almesri, Norah; College of Medicine and Medical Sciences, Arabian Gulf } \\
\text { University (AGU), Department of Biochemistry } \\
\text { Das, Nagalla; Salmaniya Medical Complex (SMC), Clinical Biochemistry } \\
\text { laboratory } \\
\text { Ali, Muhalab; College of Medicine and Medical Sciences, Arabian Gulf } \\
\text { University (AGU), Department of Biochemistry } \\
\text { Gumaa, Khalid; University College London (UCL), Division of Biosciences - } \\
\text { Cell \& Developmental Biology } \\
\text { Giha, Hayder; Arabian Gulf University (AGU), Medical Biochemistry }\end{array}$ \\
\hline Keyword: & $\begin{array}{l}\text { Obesity, Vitamin D receptor, Vitamin D binding protein, Polymorphism, } \\
\text { Bahrain }\end{array}$ \\
\hline & \\
\hline
\end{tabular}

\section{SCHOLARONE ${ }^{m}$ \\ Manuscripts}


Manuscript ID: apnm-2015-0284

Title: Independent associations of polymorphisms in vitamin D binding protein $(G C)$ and vitamin D receptor $(V D R)$ genes with obesity and plasma 25OHD3 levels demonstrate sex

\title{
dimorphism
}

\author{
Authors: Norah Almesri, ${ }^{a}$ Nagalla S Das, ${ }^{\text {b }}$ Muhallab E. Ali, ${ }^{a}$ Khalid Gumaa, ${ }^{\text {c }}$ \\ Hayder Ahmed Giha ${ }^{\text {a\# }}$
}

\section{Authors affiliations:}

${ }^{\mathrm{a}}$ Department of Biochemistry, College of Medicine and Medical Sciences (CMMS), Arabian Gulf University (AGU)

${ }^{b}$ Clinical Chemistry Laboratory, Salmaniya Medical Complex (SMC), Manama, Kingdom of Bahrain

${ }^{\mathrm{c}}$ Division of Biosciences - Cell \& Developmental Biology, University College London (UCL), London, United Kingdom

${ }^{\#}$ Corresponding author: Hayder A. Giha; Department of Medical Biochemistry, College of Medicine and Medical Sciences, Arabian Gulf University, P.O. Box: 26671, Manama, Bahrain. Phone: 0097317239 791; Fax: 973-17271090; e-mail: gehaha2002@yahoo.com 


\section{Abstract}

We investigated a possible association between polymorphisms in vitamin D binding protein $(G C)$ and vitamin D receptor $(V D R)$ genes and obesity in Bahraini adults. For this purpose, 406 subjects with varying body mass index (BMI) were selected. Plasma levels of 25hydroxyvitamin D3 (25OHD3) were measured by chemiluminescence immunoassay. Six single nucleotide polymorphisms (SNPs), two in the VDR gene (rs731236 TC and rs12721377 AG) and four in the $G C$ gene (rs2282679 AC, rs4588 CA, rs7041 GT, and rs2298849 TC), were genotyped by real time PCR. We found that the rs7041 minor allele (G) and rare genotype (GG) were associated with higher BMI ( $p=0.007$ and $p=0.012$, respectively), but they did not influence 25OHD3 levels. However, the minor alleles of rs2282679 (A) and rs4588 (C) were associated with low 25OHD3 plasma levels ( $p=0.039$ and $p=0.021$, respectively), but not with the BMI. Having categorized the subjects based on their sex, we found: i) rs7041 GG associated with high BMI in females ( $p=0.003$ ), ii) rs4588 CC associated with high BMI in females ( $p=$ $0.034)$ and low $25 \mathrm{OHD} 3$ levels in males $(p=0.009)$, and iii) rs12721377 AA associated with low 25OHD3 levels in females $(p=0.039)$. Notably, none of the common haplotypes (6 in the $G C$ gene and 3 in the $V D R$ gene) were associated with BMI. Therefore, polymorphisms in the $G C(\mathrm{rs} 2282679, \mathrm{rs} 4588, \mathrm{rs} 7041)$ and $V D R(\mathrm{rs} 12721377)$ genes were independently associated with obesity and 25OHD3 levels with a clear sex dimorphism.

Key words: obesity, vitamin D receptor, vitamin D binding protein, polymorphism, Bahrain 


\section{Introduction}

Recent epidemiological studies revealed high rates of obesity in all Gulf Cooperation Council (GCC) countries, including Bahrain. Obesity is an alarming predictor of many serious conditions, including type 2 diabetes mellitus (T2DM), heart diseases, dyslipidemia, and others (Kilpi et al. 2014). Like many complex metabolic diseases, obesity is a multifactorial disorder affected by the environmental and genetic factors. One of the environmental factors associated with obesity is vitamin D deficiency (Compston et al. 1981; Vanlint 2013). Vitamin D levels, are also affected by genetic and environmental factors (Engelman et al. 2008). It is noteworthy that both obesity and vitamin D deficiency are becoming increasingly more frequent in the GCC region (Fields et al. 2011; Musaiger 2011).

Vitamin D regulates body calcium levels and bone mineralization, and its deficiency leads to rickets and bone diseases (Greer and Marshall 1989; Stamp 1973). In the last few decades, the vitamin D endocrine system has been described (Walters 1992). Its deregulation was found to be associated with a multitude of disorders, including diabetes, insulin resistance, and obesity (Wacker and Holick 2013). Furthermore, vitamin D-related disorders may also occur on the background of normal plasma vitamin $\mathrm{D}$ levels. Thus, molecular defects downstream of the vitamin D pathway, including disturbances in plasma binding proteins (DBP), vitamin D receptors (VDR), and DNA elements, which are sites of vitamin D actions, are possibly involved in disease development (Uitterlinden et al. 2004). The DBP is encoded by the group-specific component gene $(G C)$. Allelic variations in $V D R$ and $G C$ genes were found to be associated with low circulating vitamin D levels (Engelman et al. 2008; Morrison et al. 1992).

Vitamin D has both nuclear and cytoplasmic actions (Norman 1998). In the nucleus, gene expression in target tissues is regulated via binding of $1,25(\mathrm{OH}) 2 \mathrm{D} 3$ to the specific 
cytosolic/nuclear VDR protein, a member of the steroid/thyroid hormone-receptor superfamily (Mangelsdorf et al. 1995). However, vitamin D also acts via a non-genomic pathway through the putative membrane vitamin D receptor (mVDR), which might be responsible for vitamin D rapid effects (Nemere et al. 1998).

Besides transporting vitamin D metabolites, DBP has other functions including modulation of immune and inflammatory responses, binding of fatty acids, and controlling bone development (Speeckaert et al. 2014). Polymorphisms in the $G C$ gene have specific allele distributions in different geographic areas and are associated with various disease susceptibility. Thus, DBP can be considered a novel therapeutic target (Speeckaert et al. 2014). As reviewed by Yousefzadeh et al. (2014), there are ethnicity-specific effects of $G C$ gene polymorphisms on DBP levels and vitamin D binding affinity. Engelman et al. (2008) demonstrated phenotypic variations in the DBP amino acid sequence caused by single nucleotide polymorphisms (SNPs) rs7041 and rs4588 in the $G C$ gene. Furthermore, low DBP levels were found to be associated with obesity, female sex, and age (Karlsson et al. 2014).

This study examined the possible associations between polymorphisms in genes encoding DBP (chromosome 4) and VDR (chromosome 12) proteins and vitamin D levels and obesity in native Bahraini population. 


\section{Materials and methods}

\section{Study design and subjects}

This is a cross-sectional population-based prospective study carried out in the Bahrain Defense Force (BDF) hospital, Kingdom of Bahrain. Subjects either came for regular checkups or were invited volunteers or blood donors recruited via the BDF clinical chemistry laboratory and blood bank. The participants' demographic and clinical data were recorded by means of a standardized questionnaire, interview, and physical examination. All participants were Bahraini Arabs aged between 17 and 61 years. Non-Arab or naturalized Bahraini, acutely ill patients, diabetics, pregnant or lactating females were excluded. A total of 406 subjects have been selected and grouped based on their body mass index (BMI). Table 1 describes biological characteristics of the study population. An informed consent was accepted by all participants. The study received the ethical approval from the Arabian Gulf University and BDF Hospital research and ethic committees.

\section{Blood samples collection}

Collections of almost all patient specimens were timed around regular blood draws that were part of the routine workout to prevent additional phlebotomy. Blood was collected into EDTA tubes after a vein puncture in patients who fasted overnight for 10-12 h. The buffy coat was stored separately for DNA extraction and subsequent genetic analysis. The plasma was transferred into plain tubes, acidified with 1/10 volume of $1 \mathrm{M} \mathrm{HCl}$ solution, and stored at -80 ${ }^{\circ} \mathrm{C}$ until assayed. Blood also was collected into plain tubes, the serum was separated by centrifugation and stored at $-20^{\circ} \mathrm{C}$. 


\section{Measurements of plasma vitamin D levels}

Serum 25-hydroxyvitamin D (25OHD3) concentration was measured as this is the primary circulating form of vitamin D. For the quantitative determination of 25OHD3, chemiluminescent microparticle immunoassay (CMIA) was performed using Abbott Architect analyzer according to the manufacturer's instructions. Six calibrators were used to standardize the assay and two controls (low and high) were used to monitor Internal Quality Assurance IQA.

\section{Chemiluminescent microparticle immunoassay (CMIA)}

Plasma 25OHD3 levels were measured using a standard procedure at the Salmaniya Medical Complex (SMC). A specific antibody for vitamin D was used to coat the magnetic microparticles (solid phase) and vitamin D was linked to anti-biotin acridinium conjugate. During the incubation, 25OHD3 dissociated from its binding protein and competed with labeled vitamin D for the binding sites on the antibody. After incubation, the unbound material was removed with a wash cycle. Subsequently, the starter reagents were added and a flash chemiluminescent reaction was initiated. The light signal was measured and plasma 25OHD3 levels were estimated in $\mathrm{nmol} / \mathrm{L}$.

\section{Genotyping of Vitamin D receptor $(V D R)$ and vitamin D binding protein $(G C)$ genes}

\section{DNA extraction}

Total genomic DNA was extracted from the leukocyte-rich buffy coat layer using a QIAamp DNA Blood Mini Kit (250) according to the manufacturer's specifications (Qiagen, Venlo, Netherlands). 


\section{SNPs selection}

Six SNPs were selected because in other studies they were associated with plasma 25OHD3 levels and/or with obesity or other disorders in different populations. The chosen SNPs included four $G C$ SNPs (rs2282679 AC [intron transversion substitution], rs4588 CA [missense transversion substitution], rs7041 GT [missense transversion substitution], and rs2298849 TC [intron transition substitution]) on chromosome 4. The remaining two SNPs were VDR SNPs rs731236 TC (silent transition substitution) and rs12721377 AG (intron transition substitution) on chromosome 12. We chose these SNPs also due to the relatively high minor allele frequency (MAF, 0.01 to 0.44 ) in at least some populations. All SNPs except rs2282679 AC passed the Hardy-Weinberg equilibrium test (Table 2).

\section{Real time PCR analysis}

$V D R$ and $G C$ genotyping was carried out by real-time polymerase chain reaction (rtPCR) using the Applied Biosystem (ABI) StepOne PCR System. This method is based on the detection of fluorescent signals generated proportionally during each PCR cycle. For each allele type, a TaqMan ${ }^{\circledR}$ pre-designed SNP genotyping assay kit was used. Genotyping required two steps: cycling (PCR amplification) followed by endpoint detection of fluorescent signals. Allelic discrimination was achieved by selective annealing of TaqMan ${ }^{\circledR}$ MGB probes. Results of rtPCR were used to determine homo- or heterozygosity of the studied alleles.

\section{Statistical analysis}

SigmaStat (Systat Software Inc., version 3.5. Copyright 2006) was used for data analysis. The Student's $t$-test and one-way analysis of variance were used for comparing normally distributed 
data, while Mann-Whitney rank sum test (MW) and Kruskal-Wallis one-way analysis of variance on ranks $(\mathrm{KW})$ were used for data that were not distributed normally. Chi-square test was used for comparison of rates and proportions. Pearson product-moment correlation coefficient was calculated for correlations. Differences were considered to be statistical significant if $p<0.05$.

For SNP Hardy-Weinberg Equilibrium (HWE) tests, an online calculator was used. If the calculated chi-square value was $\geq 3.841$, the hypothesis under consideration (i.e., the probability of the population being in the $\mathrm{H}-\mathrm{W}$ equilibrium for that allele) was considered true and the null hypothesis was rejected (Rodriguez et al. 2009). Haploview 4.2 program was used for calculating patterns of linkage equilibrium (LD) and haplotype selection. 


\section{Results}

\section{Minor allele frequencies (MAF) and genotype prevalence of studied polymorphisms}

As shown in Table 2, MAFs of the studied SNPs varied between 0.077 (rs12721377 AG) and 0.460 (rs7041 GT). The prevalence of rare genotypes among the tested SNPs ranged between 0.5\% (rs12721377 AG) and 14.9\% (rs2298849 TC). Genotypes of rs7041 GT, rs731236 TC, and rs2298849 TC SNPs were predominantly heterozygous $(48.5 \%, 46.2 \%$, and $45.1 \%$, respectively). The prevalence of other genotypes is shown in Table 2.

\section{Investigation of possible associations of $V D R$ and $G C$ SNP genotypes with obesity and plasma 250HD3 levels}

As indicated in Table 3, none of the genotypes of studied VDR polymorphisms (rs731236 TC and rs12721377 AG) was associated with obesity. BMI values of the carriers of rare and common homozygous and heterozygous genotypes were not significantly different $(p=0.664$ and $p=0.608$, respectively, $\mathrm{KW}$ test). With regard to $G C$ polymorphisms, subjects with the rare homozygous genotype of rs7041 GT had the highest BMI value (29.6, 26.0-34.6; median, 25\%$75 \%$ ), which was significantly higher than that of subjects with the common homozygous genotype $(27.0,23.5-31.7 ; p=0.012, \mathrm{KW}$ test $)$. Differences in BMI values between the carriers of rare and common homozygous and heterozygous genotypes for other GC SNPs (rs2282679 AC, rs4588 CA, and rs2298849 TC) were not significant. Furthermore, carriers of rare and common homozygote and heterozygote genotypes of each of the six examined SNPs had comparable levels of 25OHD3. 


\section{Associations of $V D R$ and $G C$ minor alleles with obesity and plasma 25OHD3}

The minor alleles of the two VDR polymorphisms rs731236 TC and rs12721377 AG were not associated with BMI. Among studied GC polymorphisms, only the rs7041 GT minor allele (G) was significantly stronger associated with high BMI (29.0, 25.1-33.8) compared with the nonminor allele (TT genotype; 27.0, 23.5-31.70; $p=0.007$ ). Minor alleles of other studied $G C$ polymorphisms were not associated with BMI (Fig. 1A).

Minor alleles of only two of the GC polymorphisms examined were associated with lower plasma 25OHD3 levels compared with the effect of non-minor alleles: rs2282679 (A allele [32.2, 25.2-43.1] vs. CC [35.5, 27.4-49.0], $p=0.039)$ and rs4588 (C allele [32.0, 25.2-42.2] vs. AA [35.6, 27.3-49.3], $p=0.021)($ Fig.1B).

\section{Association of $V D R$ and $G C$ haplotypes with obesity}

We used Haploview 4.2 program to identify haplotypes with a frequency $\geq 1 \%$ and to establish links between haplotypes in the two blocks $\geq 10 \%$ (Fig. 2A). None of the relatively more frequent haplotypes $(\geq 5 \%)$ in the two blocks ( 3 in the $V D R$ gene and 6 in the $G C$ gene) was associated with BMI in this setting (Table 4). The strongest links between the haplotypes in the two blocks were links of CG with CATC and ACGC and links of TG with CATC (Fig. 2B).

\section{Influence of sex on the association of $V D R$ and $G C$ genotypes with BMI and $250 H D 3$ levels}

Of the examined SNPs, only rs7041 genotypes were associated with BMI when all study subjects were pooled together (Table 3). However, after subgrouping subjects by sex, we found that the difference in BMI between the rs7041 genotypes remained statistically significant only in females $(p=0.003)$, but not in males $(p=0.797)$. Furthermore, we observed statistically 
significant differences in BMI in females with different rs4588 CA genotypes (CC, CA and AA; $p=0.034)$, but not in males $(p=0.680)$. For other SNPs, there was no sex effect on the association of genotypes with BMI (Table 5).

In addition, we observed a significant effect of sex on the association of two SNPs with 25OHD3 plasma levels (Table 5). Females with distinct rs12721377 genotypes (AA, AG, and GG) had significantly different 25OHD3 plasma levels $(p=0.039)$, whereas no such differences were detected in males with the same genotypes $(p=0.096)$. In contrast, we observed significantly different 25OHD3 plasma levels in males with distinct rs4588 genotypes (CC, CA, and AA; $\mathrm{p}=0.009)$, while no rs4588 genotype effect was noted in females $(p=0.747)$.

\section{Linkage disequilibrium (LD) between tested $V D R$ / and $G C$ polymorphisms}

As shown in Fig. 2A, rs731236 TC and rs12721377 AG, the two VDR SNPs in block 1 (chromosome 12), showed weak LD. On the other hand, the four GC SNPs showed much stronger LDs. The strongest LD was noted for rs4588 CA with rs7041 GT, followed by a slightly weaker LD for rs4588 CA with the remaining two SNPs, rs2282679 AC and rs2298849TC. The LDs between other GC SNPs were weak. The linkage of haplotypes in the two blocks, VDR and $G C$, was the strongest between CG and TG haplotypes in block $1(V D R)$ with CATC and ACGC in block $2(G C)$ (Fig. 2A, B). 


\section{Discussion}

The vitamin D endocrine system plays an important role in metabolism through genomic and non-genomic effects (Norman 1998). Available experimental evidence suggests that in addition to plasma vitamin D levels, polymorphisms of genes encoding downstream proteins in the vitamin D pathway are important factors in obesity (Jiang et al. 2007) and related metabolic abnormalities (Al-Daghri et al. 2014; Ye et al. 2001a). Our unpublished data showed that low plasma vitamin D levels were associated with obesity (manuscript in preparation). Thus, we sought to explore this association on a molecular level.

In the present study, we found associations of several $G C$ polymorphisms with plasma vitamin D level and BMI. However, the two types of associations were independent of each other. For example, the rs7041 GG genotype and rs7041 minor allele G, were significantly associated with high BMI, while none of the two was associated with vitamin D levels. In contrast, the minor alleles of the $G C$ polymorphisms rs $2282679 \mathrm{AC}$ and rs $4588 \mathrm{CA}$ were significantly associated with plasma vitamin D levels, but not with BMI. Together, these findings showed the influence of several $G C$ polymorphisms on obesity regardless of plasma vitamin D levels. However, neither of the two examined $V D R$ polymorphisms rs731236 TC and rs12721377 AG was associated with obesity or plasma vitamin D levels in this study. Furthermore, none of the 3 predominant $V D R$ haplotypes or 6 predominant $G C$ haplotypes showed any association with BMI. In addition, the combination of SNP minor alleles, which showed association with BMI or with plasma 25OHD3 levels, failed to demonstrate any association with BMI (data not shown). Although several studies indicated the influence of polymorphisms of genes in vitamin D pathway in obesity (Foucan et al. 20113; Jiang et al. 2007), one study concluded that "vitamin D 
pathway genes are unlikely to have a major role in obesity-related traits in the general population" (Vimaleswaran et al. 2013).

Among the tested SNPs in this study, the $G C$ polymorphism rs7041 GT had the strongest association with obesity. However, neither the minor allele nor genotypes of this SNP were associated with plasma 25OHD3 levels. This SNP was found to be associated with low 25OHD3 plasma levels in several ethnic groups, including African Americans (Engelman et al. 2008), Chinese in Singapore (Robien et al. 2013), and Europeans with T2DM (Strawbridge et al. 2014). Although it was not associated with obesity in our study, the rs4588 minor allele CA, (but not the genotypes), was significantly associated with low plasma vitamin D levels. The association of the rs4588 CA SNP with vitamin D levels was also recognized in other studies that involved different ethnic populations, e.g., African Americans (Engelman et al. 2008), Chinese in Singapore (Robien et al. 2013), and Danish (Nissen et al. 2014). Interestingly, rs7041 GT was in strong LD with rs4588 CA, but not with the remaining two GC SNPs, while rs4588 CA was the only SNP in this study that was in strong LD with all GC SNPs.

We found that a minor allele of another $G C$ polymorphism, rs2282679 AC, was significantly associated with low plasma vitamin D levels. In a genome-wide association study of 16 cohorts from Europe, the rs2282679 SNP was found to be significantly associated with 25OHD3 deficiency (Wang et al. 2010). Other studies also showed the association of this SNP with plasma vitamin D levels in different populations, e.g., in Japanese (Yoshida et al. 2014), French (Foucan et al. 2013), Danish (Nissen et al. 2014), Europeans with T2DM (Strawbridge et al. 2014), and African Americans (Signorello et al. 2011). Exceptionally, rs2282679 AC was the only SNP in this study, which was not in HWE, but still in strong LD with rs4588 CA. The only examined $G C$ polymorphism without any association with obesity or plasma vitamin D levels 
was rs2298849 TC. A significant association of this SNP with plasma vitamin D levels has been reported in several other ethnic groups, including Chinese Han (Zhang et al. 2012), Chinese in Singapore (Robien et al. 2013), French (Foucan et al. 2013), and African Americans (Signorello et al. 2011).

Although associations of plasma vitamin D levels with several SNPs in the $G C$ gene in this and other studies were remarkable, there is no known direct role for DBP in vitamin D synthesis or catabolism. Indeed, DBP is the blood carrier of vitamin D and its defects can affect circulating vitamin levels and reduce active vitamin D concentration in target tissues. The vitamin Dindependent effect of $G C$ polymorphisms on obesity is interesting and may be a novel observation, at least in the region. It complements previously known effects of DBP on immune and inflammatory responses, binding of fatty acids, and other physiological and biochemical parameters (Speeckaert et al. 2014). However, at present we cannot provide a mechanistic evidence to explain our observation, thus further studies of effects of $G C$ polymorphisms on obesity are needed.

None of the two examined VDR polymorphisms, rs731236 TC and rs12721377 AG, was associated with obesity or plasma vitamin D levels in this study. The former SNP was found to be associated with obesity in the Greek population (Vasilopoulos et al. 2013), French Caucasians with early onset of T2DM (Ye et al. 2001b), and children and adolescents in Brazil (Ferrarezi et al. 2012). In addition, rs731236 TC was reported to be associated with vitamin D deficiency in Brazilian girls (Santos et al. 2012). In contrast, rs12721377 AG was not associated with obesity or vitamin D level in this study nor with other disorders, such as T2DM (Kahles et al. 2009) or prostatic cancer (Bonilla et al. 2011) as explored by others. We selected rs12721377 AG as a control SNP, as it had the lowest MAF, was located in an intron, and represented transition 
substitution SNP type. The two chosen VDR SNPs were not in LD, although both are located on chromosome 12.

Our unpublished data suggested a sex-dependent association between plasma vitamin D levels and obesity, as well as showed lower plasma vitamin D levels in females compared to males (manuscript in preparation). The association of vitamin D deficiency with sex was previously reported (Valtueña et al. 2013), especially in morbid obesity (Johnson et al. 2012). Accordingly, we reanalyzed the association of both $G C$ and $V D R$ polymorphisms with obesity (BMI) and 25OHD3 levels in males and females separately. The obtained results were intriguing, as the least prevalent polymorphism, rs12721377 AG, which was not associated with 25OHD3 levels or BMI when all subjects were pooled, showed a significant association with lower 25OHD3 plasma levels for the rare genotype (AA) in females only. Similar sex-dependent association with vitamin D levels was observed in females with the rs4588 CA genotype, but not in the male group. Association of the same SNPs with BMI also showed sex dependence. The abovementioned association of rs7041 GT genotypes with BMI in the total study population remained significant only in females, when each sex in considered separately. Furthermore, a significant association of BMI with rs4588 CA genotypes was also limited only to females. Collectively, these results revealed differential sex-dependent associations of BMI and vitamin D levels with examined $V D R$ and $G C$ polymorphisms. Effects of SNP sex dimorphisms on obesity (Luque-Ramírez et al. 2013; White and Tchoukalova 2014) and insulin resistance (JiménezPavón et al., 2014) has been previously reported. Effects of sex dimorphism related to polymorphism on obesity can be explained, in part, by the role of sex hormones in energy production and brown fat metabolism (Quarta et al. 2012). At the same time, genetic and sociocultural factors also need to be considered. In this regard, Bahrainis, as most of other Arabs in 
the Gulf region, are prone to obesity and vitamin D deficiency because of the social and cultural norms especially prevalent among females, e.g., adherence to conservative dressing, minimal exposure to the sunlight, and lack of active exercise. Finally, one of the implications of the present study is that screening for plasma vitamin D deficiency in obesity and/or other metabolic disorders should be accompanied by monitoring polymorphisms in genes encoding downstream vitamin D metabolism pathway proteins, such as VDR and DBP. This monitoring may be of special importance in the Middle East because of the high rate of consanguinity, which leads to clustering of polymorphisms in families.

\section{Conclusions}

In summary, both the minor allele and rare genotype of the rs7014 GT were found to be associated with obesity (high BMI), while they did not affect plasma vitamin D (25OHD3) levels. In addition, the minor alleles of rs2282679 AC and rs4588 CA SNPs were associated with lower vitamin D levels, but had no effect on obesity. However, when males and females were considered separately, the above associations remained significant only in subjects of one of the two sexes. Separate analysis of same sex subjects also uncovered additional significant associations. Two major conclusions can be reached from our observations: i) the influence of $G C$ polymorphisms on obesity can be independent of their effect in plasma vitamin D levels, and ii) association of $G C$ and $V D R$ polymorphisms with obesity and vitamin D levels shows sex dimorphism in Bahraini Arabs. Both sets of findings will need further experimental verification and validation in larger cohorts of subjects. 


\section{Acknowledgments}

Contribution of study subjects (volunteers) to this study is greatly appreciated. We are extremely grateful to the health authorities of the Bahrain Defense Force hospital, in particular, to Dr. Ahmed Alansari for welcoming, accommodating, and supporting this study. The effort of the staff of the clinical chemistry lab and blood bank at the Bahrain Defense Force hospital in sample collection was indispensable and is highly appreciated. We would like to acknowledge technical support of Mr. Ali Al Mahmeed of the Department of Microbiology at the Arabian Gulf University (AGU). The master student Norah Almesri and Dr. Hayder A. Giha received support from the AGU throughout the duration of this study (AGU grant 74-2011).

\section{Disclosure}

\section{Declaration of conflict of interest}

None of the authors had any potential conflicts of interest associated with this research.

\section{Funding}

This work was supported exclusively by the Arabian Gulf University, Kingdom of Bahrain (grant number 74-2011). 


\section{References}

Al-Daghri, N.M., Al-Attas, O.S., Alkharfy, K.M., Khan, N., Mohammed, A.K., Vinodson, B., Ansari, M.G., Alenad, A., and Alokail, M.S. 2014. Association of VDR-gene variants with factors related to the metabolic syndrome, type 2 diabetes and vitamin D deficiency. Gene 542(2): 129-133. doi: 10.1016/j.gene.2014.03.044. PMID: 24680778.

Bonilla, C., Hooker, S., Mason, T., Bock, C.H., and Kittles, R.A. 2011. Prostate cancer susceptibility Loci identified on chromosome 12 in African Americans. PLoS One 6(2): e16044. doi: 10.1371/journal.pone.0016044. PMID: 21358824.

Compston, J.E., Vedi, S., Ledger, J.E., Webb, A., Gazet, J.C., and Pilkington, T.R. 1981. Vitamin D status and bone histomorphometry in gross obesity. Am. J. Clin. Nutr. 34(11): 2359-2363. PMID: 7304477.

Engelman, C.D., Fingerlin, T.E., Langefeld, C.D., Hicks, P.J., Rich, S.S., Wagenknecht, L.E., Bowden, D.W., and Norris, J.M. 2008. Genetic and environmental determinants of 25hydroxyvitamin D and 1,25-dihydroxyvitamin D levels in Hispanic and African Americans. J. Clin. Endocrinol. Metab. 93(9): 3381-3388. doi: 10.1038/ajh.2009.88. PMID: 18593774. Ferrarezi, D.A., Bellili-Muñoz, N., Nicolau, C., Cheurfa, N., Guazzelli, I.C., Frazzatto, E., Velho, G., and Villares S.M. 2012. Allelic variations in the vitamin D receptor gene, insulin secretion and parents' heights are independently associated with height in obese children and adolescents. Metabolism 61(10): 1413-1421. doi: 10.1016/j.metabol.2012.03.018. PMID: $\underline{22551951 .}$.

Fields, J., Trivedi, N.J., Horton, E., and Mechanick, J.I. 2011. Vitamin D in the Persian Gulf: integrative physiology and socioeconomic factors. Curr. Osteoporos. Rep. 9(4): 243-250. doi: 10.1007/s11914-011-0071-2. PMID: 21901427. 
Foucan, L., Vélayoudom-Céphise, F.L., Larifla, L., Armand, C., Deloumeaux, J., Fagour, C., Plumasseau, J., Portlis, M.L., Liu, L., Bonnet, F., and Ducros, J. 2013. Polymorphisms in GC and NADSYN1 Genes are associated with vitamin D status and metabolic profile in Nondiabetic adults. BMC Endocr. Disord. 13(1):36. doi: 10.1186/1472-6823-13-36. PMID: $\underline{24073860 .}$.

Greer, F.R., and Marshall, S. 1989. Bone mineral content, serum vitamin D metabolite concentrations, and ultraviolet B light exposure in infants fed human milk with and without vitamin D2 supplements. J. Pediatr. 114(2): 204-212. PMID: 2783734.

Jiang, H., Xiong, D.H., Guo, Y.F., Shen, H., Xiao, P., Yang, F., Chen, Y., Zhang, F., Recker, R.R., and Deng, H.W. 2007. Association analysis of vitamin D-binding protein gene polymorphisms with variations of obesity-related traits in Caucasian nuclear families. Int. J. Obes. (Lond). 31(8): 1319-1324. PMID: 17342072.

Jiménez-Pavón, D., Sesé, M.A., Valtueña, J., Cuenca-García, M., González-Gross, M., Gottrand, F., Kafatos, A., Manios, Y., Widhalm, K., de Henauw, S., Polito, A., Pérez-López, F.R., and Moreno, L.A. 2014. Leptin, vitamin D, and cardiorespiratory fitness as risk factors for insulin resistance in European adolescents: gender differences in the HELENA Study. Appl. Physiol. Nutr. Metab. 39(5): 530-537. doi: 10.1139/apnm-2013-0250. PMID: 24766234.

Johnson, L.K., Hofsø, D., Aasheim, E.T., Tanbo, T., Holven, K.B., Andersen, L.F., Røislien, J., and Hjelmesæth, J. 2012. Impact of gender on vitamin D deficiency in morbidly obese patients: a cross-sectional study. Eur. J. Clin. Nutr. 66(1): 83-90. doi:

10.1038/ejen.2011.140. PMID: 21792214. 
Kahles, H., Morahan, G., Todd, J.A., Badenhoop, K., and Type I Diabetes Genetics Consortium. 2009. Association analyses of the vitamin D receptor gene in 1654 families with type I diabetes. Genes Immun. 10(Suppl 1): S60-3. doi: 10.1038/gene.2009.93. PMID: 19956103.

Karlsson, T., Osmancevic, A., Jansson, N., Hulthén, L., Holmäng, A., and Larsson, I. 2014. Increased vitamin D-binding protein and decreased free $25(\mathrm{OH}) \mathrm{D}$ in obese women of reproductive age. Eur. J. Nutr. 53(1): 259-267. doi: 10.1007/s00394-013-0524-8. PMID: 23604494.

Kilpi, F., Webber, L., Musaigner, A., Aitsi-Selmi, A., Marsh, T., Rtveladze, K., McPherson, K., and Brown, M. 2014. Alarming predictions for obesity and non-communicable diseases in the Middle East. Public Health Nutr. 17(5): 1078-1086. doi: 10.1017/S1368980013000840. PMID: 23642403.

Luque-Ramírez, M., Martínez-García, M.Á., Montes-Nieto, R., Fernández-Durán, E., Insenser, M., Alpañés, M., and Escobar-Morreale, H.F. 2013. Sexual dimorphism in adipose tissue function as evidenced by circulating adipokine concentrations in the fasting state and after an oral glucose challenge. Hum. Reprod. 28(7): 1908-1918. doi: 10.1093/humrep/det097. PMID: 23559188.

Mangelsdorf, D.J., Thummel, C., Beato, M., Herrlich, P., Schütz, G., Umesono, K., Blumberg, B., Kastner, P., Mark, M., Chambon, P., and Evans, R.M. 1995. The nuclear receptor superfamily: the second decade. Cell 83(6): 835-839. PMID: $\underline{8521507 .}$

Morrison, N.A., Yeoman, R., Kelly, P.J., and Eisman, J.A. 1992. Contribution of trans-acting factor alleles to normal physiological variability: vitamin D receptor gene polymorphisms and circulating osteocalcin. Proc. Natl. Acad. Sci. USA 89(15): 6665-6669. PMID: 1353882. 
Musaiger, A.O. 2011. Overweight and obesity in Eastern Mediterranean region: prevalence and possible causes. J. Obes. 2011: 407237. doi: 10.1155/2011/407237. PMID: 21941635.

Nemere, I., Schwartz, Z., Pedrozo, H., Sylvia, V.L., Dean, D.D., and Boyan, B.D. 1998. Identification of a membrane receptor for 1,25-dihydroxyvitamin D3 which mediates rapid activation of protein kinase C. J. Bone Miner. Res. 13(9): 1353-1359. PMID: $\underline{9738506}$.

Nissen, J., Rasmussen, L.B., Ravn-Haren, G., Andersen, E.W., Hansen, B., Andersen, R., Mejborn, H., Madsen, K.H., and Vogel, U. 2014. Common variants in CYP2R1 and GC genes predict vitamin D concentrations in healthy Danish children and adults. PLoS One 9(2): e89907. doi: 10.1371/journal.pone.0089907. PMID: 24587115.

Norman, A.W. 1998. Receptors for 1,25(OH)2D3: past, present, and future. J. Bone Miner. Res. 13(9): 1360-1369. PMID: 9738507.

Quarta, C., Mazza, R., Pasquali, R., and Pagotto, U. 2012. Role of sex hormones in modulation of brown adipose tissue activity. J. Mol. Endocrinol. 49(1): R1-7. doi: 10.1530/JME-120043. PMID: 22460126.

Robien, K., Butler, L.M., Wang, R., Beckman, K.B., Walek, D., Koh, W.P., and Yuan, J.M. 2013. Genetic and environmental predictors of serum 25-hydroxyvitamin D concentrations among middle-aged and elderly Chinese in Singapore. Br. J. Nutr. 109(3): 493-502. doi: 10.1017/S0007114512001675. PMID: 22583563.

Rodriguez, S., Gaunt, T.R., and Day, I.N. 2009. Hardy-Weinberg equilibrium testing of biological ascertainment for Mendelian randomization studies. Am. J. Epidemiol. 169(4): 505-514. doi: 10.1093/aje/kwn359. PMID: 19126586.

Santos, B.R., Mascarenhas, L.P., Satler, F., Boguszewski, M.C., and Spritzer, P.M. 2012. Vitamin D deficiency in girls from South Brazil: a cross-sectional study on prevalence and 
association with vitamin D receptor gene variants. BMC Pediatr. 12: 62. doi: 10.1186/14712431-12-62. PMID: 22681928.

Signorello, L.B., Shi, J., Cai, Q., Zheng, W., Williams, S.M., Long, J., Cohen, S.S., Li, G., Hollis, B.W., Smith, J.R., and Blot, W.J. 2011. Common variation in vitamin D pathway genes predicts circulating 25-hydroxyvitamin D Levels among African Americans. PLoS One 6(12): e28623. doi: 10.1371/journal.pone.0028623. PMID: 22205958.

Speeckaert, M.M., Speeckaert, R., van Geel, N., and Delanghe, J.R. 2014. Vitamin D binding protein: a multifunctional protein of clinical importance. Adv. Clin. Chem. 63: 1-57. PMID: $\underline{24783350 .}$.

Stamp, T.C. 1973. Vitamin D metabolism. Recent advances. Arch. Dis. Child. 48(1): 2-7. PMID: $\underline{4346640 .}$.

Strawbridge, R.J., Deleskog, A., McLeod, O., Folkersen, L., Kavousi, M., Gertow, K., Baldassarre, D., Veglia, F., Leander, K., Gigante, B., Kauhanen, J., Rauramaa, R., Smit, A.J., Mannarino, E., Giral, P., Dehghan, A., Hofman, A., Franco, O.H., Humphries, S.E., Tremoli, E., de Faire, U., Gustafsson, S., Östensson, C.G., Eriksson, P., Öhrvik, J., and Hamsten, A. 2014. A serum 25-hydroxyvitamin D concentration-associated genetic variant in DHCR7 interacts with type 2 diabetes status to influence subclinical atherosclerosis (measured by carotid intima-media thickness). Diabetologia 57(6): 1159-1172. doi: 10.1007/s00125-0143215-y. PMID: 24663808.

Uitterlinden, A.G., Fang, Y., van Meurs, J.B., van Leeuwen, H., and Pols, H.A. 2004. Vitamin D receptor gene polymorphisms in relation to Vitamin D related disease states. J. Steroid Biochem. Mol. Biol. 89-90(1-5): 187-193. PMID: 15225770. 
Valtueña, J., González-Gross, M., Huybrechts, I., Breidenassel, C., Ferrari, M., Mouratidou, T., Gottrand, F., Dallongeville, J., Azzini, E., Sioen, I., Gómez-Martínez, S., Cuenca-García, M., Kersting, M., Stehle, P., Kafatos, A., Manios, Y., Widhalm, K., and Moreno, L.A. 2013. Factors associated with vitamin D deficiency in European adolescents: the HELENA study. J. Nutr. Sci. Vitaminol. (Tokyo) 59(3): 161-171. PMID: 23883686.

Vanlint, S. 2013. Vitamin D and obesity. Nutrients 5(3): 949-956. doi: 10.3390/nu5030949. PMID: 23519290.

Vasilopoulos, Y., Sarafidou, T., Kotsa, K., Papadimitriou, M., Goutzelas, Y., Stamatis, C., Bagiatis, V., Tsekmekidou, X, Yovos, J.G., and Mamuris, Z. 2013. VDR TaqI is associated with obesity in the Greek population. Gene 512(2): 237-239. doi:

10.1016/j.gene.2012.10.044. PMID: 23103831.

Vimaleswaran, K.S., Cavadino, A., Berry, D.J., Genetic Investigation of Anthropometric Traits (GIANT) Consortium, Whittaker, J.C., Power, C., Järvelin, M.R., and Hyppönen, E. 2013. Genetic association analysis of vitamin D pathway with obesity traits. Int. J. Obes. (Lond). 37(10): 1399-1406. doi: 10.1038/ijo.2013.6. PMID: 23381556.

Wacker, M., and Holick, M.F. 2013. Sunlight and Vitamin D: A global perspective for health. Dermatoendocrinol. 5(1): 51-108. doi: 10.4161/derm.24494. PMID: 24494042.

Walters, M.R. 1992. Newly identified actions of the vitamin D endocrine system. Endocr. Rev. 13(4): 719-764. PMID: 1333949.

Wang, T.J., Zhang, F., Richards, J.B., Kestenbaum, B., van Meurs, J.B., Berry, D., Kiel, D.P., et al. 2010. Common genetic determinants of vitamin D insufficiency: a genome-wide association study. Lancet 376(9736): 180-188. doi: 10.1016/S0140-6736(10)60588-0. PMID: 20541252. 
White, U.A., and Tchoukalova, Y.D. 2014. Sex dimorphism and depot differences in adipose tissue function. Biochim. Biophys. Acta 1842(3): 377-392. doi: 10.1016/j.bbadis.2013.05.006. PMID: 23684841.

Yach, D., Stuckler, D., and Brownell, K.D. (2006) Epidemiologic and economic consequences of the global epidemics of obesity and diabetes. Nat. Med. 12(1): 62-66. PMID: 16397571.

Ye, W.Z., Dubois-Laforgue, D., Bellanné-Chantelot, C., Timsit, J., and Velho, G. 2001a. Variations in the vitamin D-binding protein (Gc locus) and risk of type 2 diabetes mellitus in French Caucasians. Metabolism 50(3): 366-369. PMID: 11230793.

Ye, W.Z., Reis, A.F., Dubois-Laforgue, D., Bellanné-Chantelot, C., Timsit, J., and Velho, G. 2001b. Vitamin D receptor gene polymorphisms are associated with obesity in type 2 diabetic subjects with early age of onset. Eur. J. Endocrinol. 145(2): 181-186. PMID: 11454514.

Yoshida, S., Ikari, K., Furuya, T., Toyama, Y., Taniguchi, A., Yamanaka, H., and Momohara, S. 2014. A GC polymorphism associated with serum 25-hydroxyvitamin D level is a risk factor for hip fracture in Japanese patients with rheumatoid arthritis: 10-year follow-up of the Institute of Rheumatology, Rheumatoid Arthritis cohort study. Arthritis Res. Ther. 16(2): R75. doi: $\underline{10.1186 / \operatorname{ar} 4516 .}$.

Yousefzadeh, P., Shapses, S.A., and Wang, X. 2014. Vitamin D Binding Protein Impact on 25Hydroxyvitamin D Levels under Different Physiologic and Pathologic Conditions. Int. J. Endocrinol. 2014:981581. doi: 10.1155/2014/981581. PMID: 24868205.

Zhang, Y., Wang, X., Liu, Y., Qu, H., Qu S., Wang, W., and Ren, L. 2012. The GC, CYP2R1 and DHCR7 genes are associated with vitamin D levels in northeastern Han Chinese children. Swiss Med. Wkly 142: w13636. doi: $\underline{\text { 10.4414/smw.2012.13636. PMID: } 22801813 .}$. 
Table 1. Biological characteristics of the study population

\begin{tabular}{|c|c|c|c|}
\hline Parameter & Range ( & $\begin{array}{l}\text { Females } \\
\mathrm{n} \pm \mathrm{SD} \\
\text { in. }-\max .)\end{array}$ & $p$-value, test \\
\hline Number & 212 & 194 & \\
\hline $\operatorname{BMI}\left(\mathrm{kg} / \mathrm{m}^{2}\right)$ & $28.93 \pm 5.93(18.34-48.11)$ & $30.07 \pm 7.85(16.93-57.21)$ & $0.256, \mathrm{MW}$ \\
\hline Age (years) & $34.26 \pm 10.46(18.00-58.00)$ & $33.88 \pm 11.26(17.00-61.00)$ & $0.581, \mathrm{MW}$ \\
\hline \multicolumn{4}{|l|}{ Plasma 25OHD3 (nmol/L) } \\
\hline Mean \pm SD & $42.45 \pm 13.39$ & $30.87 \pm 12.65$ & $<0.001, \mathrm{MW}$ \\
\hline Range & $(2.60-87.50)$ & $(11.00-100.00)$ & \\
\hline Number & $(\mathrm{n}=164)$ & $(n=150)$ & \\
\hline FBG (mmol/L) & $5.60 \pm 0.99(3.88-10.03)$ & $5.57 \pm 1.43(3.40-19.31)$ & $0.322, \mathrm{MW}$ \\
\hline $\mathrm{HbAlc}(\mathrm{mmol} / \mathrm{mol})$ & $36.83 \pm 5.67(9.00-69.00)$ & $37.74 \pm 6.56(25.00-90.00)$ & $0.111, \mathrm{MW}$ \\
\hline T. cholesterol (mmol/L) & $5.03 \pm 1.16(2.60-10.66)$ & $4.89 \pm 0.90(2.50-7.30)$ & $0.332, \mathrm{MW}$ \\
\hline LDLC (mmol/L) & $3.13 \pm 1.03(1.16-9.02)$ & $2.87 \pm 0.76(1.19-5.26)$ & $0.008, \mathrm{MW}$ \\
\hline $\operatorname{HDLC}(\mathrm{mmol} / \mathrm{L})$ & $1.12 \pm 0.40(0.01-4.10)$ & $1.35 \pm 0.39(0.04-3.50)$ & $<0.001, \mathrm{MW}$ \\
\hline TAG (mmol/L) & $1.58 \pm 1.03(0.03-6.91)$ & $1.30 \pm 1.12(0.30-12.94)$ & $<0.001, \mathrm{MW}$ \\
\hline
\end{tabular}

Footnote: values are expressed as the mean $\pm \mathrm{SD}$, range (min-max)

Statistical test used: Mann-Whitney rank sum test (MW) 
Table 2. Minor allele frequencies (MAFs) and genotype prevalence of the vitamin D receptor $(V D R)$ and vitamin D binding protein $(G C)$ gene single nucleotide polymorphisms (SNPs) and their Hardy-Weinberg equilibrium (HWE) in adult Bahrainis

\begin{tabular}{|c|c|c|c|c|c|}
\hline \multirow{2}{*}{$\begin{array}{l}\text { SNP } \\
\text { Study subjects }\end{array}$} & \multirow[t]{2}{*}{ MAF } & \multicolumn{3}{|c|}{ Genotype prevalence } & \multirow[t]{2}{*}{$\mathrm{HWE}, X^{2}$} \\
\hline & & $\begin{array}{l}\text { Homozygote } \\
\text { (rare) }\end{array}$ & Heterozygote & $\begin{array}{l}\text { Homozygote } \\
\text { (common) }\end{array}$ & \\
\hline rs731236 T/C (385) & $0.351(270 / 770)$ & $11.9 \%(46)$ & $46.2 \%(178)$ & $41.8 \%(161)$ & 0.09 \\
\hline rs12721377 A/G (390) & $0.077(60 / 780)$ & $0.5 \%(2)$ & $14.4 \%(56)$ & $85.1 \%(332)$ & 0.05 \\
\hline rs2282679 A/C (397) & $0.300(238 / 794)$ & $12.1 \%(48)$ & $35.8 \%(142)$ & $52.1 \%(207)$ & 8.69 \\
\hline rs4588 C/A (391) & $0.219(171 / 782)$ & $4.6 \%(18)$ & $34.5 \%(135)$ & $60.9 \%(238)$ & 0.04 \\
\hline rs7041 G/T (390) & $0.460(359 / 780)$ & $21.8 \%(85)$ & $48.5 \%(189)$ & $29.7 \%(116)$ & 0.24 \\
\hline rs2298849 T/C (388) & $0.375(291 / 776)$ & $14.9 \%(58)$ & $45.1 \%(175)$ & $39.9 \%(155)$ & 0.55 \\
\hline
\end{tabular}

Numbers in brackets represent numbers of test samples (i.e., numbers of study subjects).

$X^{2}:$ the value of the chi-square statistic 
Table 3. BMI and plasma 25OHD3 levels in carriers of rare and common homozygous and heterozygous genotypes for each $G C$ and $V D R$ polymorphism examined

\begin{tabular}{|c|c|c|c|c|}
\hline \multirow[b]{2}{*}{ Carriers } & \multicolumn{3}{|c|}{ Genotypes } & \multirow{2}{*}{$\begin{array}{c}p \text {-value } \\
\mathrm{KW}\end{array}$} \\
\hline & Rare homozygous & Heterozygous & Common homozygous & \\
\hline \multicolumn{5}{|c|}{ Vitamin D receptor gene $(V D R)$ SNPs } \\
\hline rs731236 TC & TT & $\mathrm{TC}$ & $\mathrm{CC}$ & \\
\hline BMI (385) & $30.0,25.2-33.2(46)$ & $28.4,24.9-32.8(178)$ & $28.4,24.4-33.5(161)$ & 0.664 \\
\hline 25OHD3 (296) & $35.5,27.6-45.2(33)$ & $35.0,27.5-47.1(143)$ & $32.8,25.1-46.2(120)$ & 0.342 \\
\hline rs 12721377 AG & AA & AG & GG & \\
\hline BMI (390) & $28.9,20.6-37.2(2)$ & $27.1,24.3-32.1(56)$ & $28.6,24.9-33.3(332)$ & 0.608 \\
\hline 25OHD3 (390) & $32.6,19.4-45.7(2)$ & $35.2,23.8-50.1(38)$ & $34.3,26.4-45.1)(260)$ & 0.856 \\
\hline \multicolumn{5}{|c|}{ Vitamin D binding protein gene $(G C)$ SNPs } \\
\hline rs2282679 AC & AA & $\mathrm{AC}$ & $\mathrm{CC}$ & \\
\hline BMI (397) & $28.4,25.0-32.6(48)$ & $28.8,24.8-33.5(142)$ & $28.4,24.4-33.0(207)$ & 0.634 \\
\hline 25OHD3 (397) & $31.8,26.6-46.6(10)$ & $32.2,25.1-42.8(110)$ & $35.5,27.4-49.0(185)$ & 0.105 \\
\hline rs4588 CA & $\mathrm{CC}$ & $\mathrm{CA}$ & AA & \\
\hline BMI (391) & $30.7,26.4-35.3(18)$ & $28.6,24.6-33.0(135)$ & $28.4,24.7-33.2(238)$ & 0.345 \\
\hline 25OHD3 (391) & $32.6,27.0-41.5(13)$ & $31.9,25.2-42.9(105)$ & $35.6,27.3-49.3(182)$ & 0.070 \\
\hline rs7041 GT & GG & GT & TT & \\
\hline BMI (390) & $29.6,26.0-34.6(85)$ & $28.7,24.6-33.5$ (189) & 27.0, 23.5-31.7 (116) & 0.012 \\
\hline 25OHD3 (390) & $32.7,25.6-44.2(64)$ & $35.2,26.3-48.9(150)$ & $34.3,27.0-46.5(85)$ & 0.437 \\
\hline rs2298849 TC & TT & $\mathrm{TC}$ & $\mathrm{CC}$ & \\
\hline T/C BMI (388) & $30.3,25.5-32.9(58)$ & $28.0,24.5-33.2(175)$ & $28.6,24.6-33.5(155)$ & 0.297 \\
\hline 25OHD3 (388) & $36.7,28.6-49.9(16)$ & $35.2,25.5-48.2(142)$ & $33.4,26.8-42.9(142)$ & 0.580 \\
\hline
\end{tabular}


Numbers in brackets represent numbers of test samples (i.e., numbers of study subjects). KW:

Kruskal-Wallis one-way analysis of variance on ranks test. BMI $\left(\mathrm{kg} / \mathrm{m}^{2}\right), 25 \mathrm{OHD} 3(\mathrm{nmol} / \mathrm{L})$ 
Table 4. Haplotypes of vitamin D receptor $(V D R)$ and vitamin D binding protein $(G C)$ gene polymorphisms: prevalence and association with BMI in Bahraini adults

\begin{tabular}{lccc}
\hline Haplotype & Prevalence & BMI $\left(\mathrm{kg} / \mathrm{m}^{2}\right)$ & $p$ value \\
\cline { 2 - 3 } & & Haplotype & MW \\
& carrier & non-carrier & \\
\hline
\end{tabular}

\begin{tabular}{lcccc}
\hline \multicolumn{5}{l}{ Vitamin D receptor gene (two SNPs) } \\
\hline CG & 0.588 & $28.4,24.8-33.4(335)$ & $29.7,25.1-33.2(45)$ & 0.474 \\
TG & 0.335 & $28.6,25.0-32.8(220)$ & $28.5,24.5-33.5(160)$ & 0.974 \\
CA & 0.061 & $27.1,23.6-33.2(53)$ & $28.7,25.0-33.3(327)$ & 0.190 \\
Vitamin D bind protein gene (four SNPs) & & \\
CATC & 0.317 & $28.2,24.4-33.3(240)$ & $29.4,25.5-34.1(137)$ & 0.052 \\
ACGC & 0.171 & $28.7,24.8-34.2(133)$ & $28.5,24.7-33.1(244)$ & 0.493 \\
CAGT & 0.134 & $28.9,25.2-33.5(141)$ & $28.4,24.6-33.3(236)$ & 0.187 \\
CATT & 0.129 & $28.6,25.1-33.4(145)$ & $28.4,24.7-33.3(232)$ & 0.530 \\
CAGC & 0.091 & $28.7,24.7-33.5(203)$ & $28.4,24.9-33.0(174)$ & 0.413 \\
AATT & 0.079 & $28.4,24.8-31.6(83)$ & $28.6,24.8-33.5(294)$ & 0.845 \\
\hline
\end{tabular}

Numbers in brackets represent numbers of test samples (i.e., numbers of study subjects).

MW: Mann-Whitney rank sum test. Numerical values represent the median and $25-75 \%$ percentile range. 
Table 5. Comparisons of BMI and plasma 25OHD3 levels in study subjects with different genotypes of vitamin D receptor $(V D R)$ and vitamin D binding protein $(G C)$ gene single nucleotide polymorphisms (SNPs). Male and female subjects are considered separately.

\begin{tabular}{|c|c|c|c|c|}
\hline \multirow[t]{2}{*}{ SNP genotypes } & \multicolumn{2}{|c|}{$\operatorname{BMI}\left(\mathrm{kg} / \mathrm{m}^{2}\right)$} & \multicolumn{2}{|c|}{ Plasma 25OHD3 level (nmol/L) } \\
\hline & Males & Females & Males & Females \\
\hline \multirow[t]{2}{*}{ All subjects } & $28.3,24.8-31.8$ & $28.9,24.5-33.9$ & $41.1,32.7-52.2$ & $28.0,22.7-35.0$ \\
\hline & \multicolumn{2}{|c|}{$p=0.256$} & \multicolumn{2}{|c|}{$p<0.001$} \\
\hline \multicolumn{5}{|l|}{ rs $731236 \mathrm{TC}$} \\
\hline $\mathrm{TT}$ & $29.2,24.8-32.8(28)$ & $31.2,26.7-33.3(18)$ & $42.9 \pm 13.4(16)$ & $33.9,24.7-38.4(17)$ \\
\hline $\mathrm{TC}$ & $27.8,24.8-31.0(91)$ & $29.0,25.3-34.8(87)$ & $43.0 \pm 13.2(74)$ & $28.8,23.5-37.2(69)$ \\
\hline \multirow[t]{2}{*}{$\mathrm{CC}$} & $28.6,25.2-33.0(81)$ & $28.2,23.9-33.6(80)$ & $42.4 \pm 13.8(62)$ & $25.4,21.0-32.8(58)$ \\
\hline & $p=0.382$ & $p=0.412$ & $p=0.968^{*}$ & $p=0.118$ \\
\hline \multicolumn{5}{|l|}{ rs12721377 AG } \\
\hline AA & $37.2,37.2-37.2(1)$ & $20.6,20.6-20.6(1)$ & $45.7 \pm 0.0(1)$ & $19.4,19.4-19.4(1)$ \\
\hline $\mathrm{AG}$ & $27.1,24.8-29.7(30)$ & $29.6,2.9-36.5(26)$ & $47.2 \pm 12.4(22)$ & $23.2,21.9-28.1(16)$ \\
\hline \multirow[t]{2}{*}{ GG } & $28.4,24.8-32.4(171)$ & $29.0,24.9-33.8(161)$ & $42.0 \pm 13.6(132)$ & $29.0,23.7-36.1(128)$ \\
\hline & $p=0.249$ & $p=0.331$ & $p=0.096^{*}$ & $p=0.039$ \\
\hline \multicolumn{5}{|l|}{ rs2282679 AC } \\
\hline AA & $27.5,24.9-31.6(27)$ & $30.5,24.7-35.1(21)$ & $39.4 \pm 12.5(6)$ & $27.4,22.1-45.5(4)$ \\
\hline $\mathrm{AC}$ & $27.8,24.2-31.3(76)$ & $30.3,26.1-34.6(66)$ & $39.8 \pm 13.6(58)$ & $27.0,22.6-33.3(52)$ \\
\hline \multirow[t]{2}{*}{$\mathrm{CC}$} & $28.6,25.2-32.7(103)$ & $28.2,23.5-33.3(104)$ & $44.7 \pm 13.0(94)$ & $28.3,22.8-38.1(91)$ \\
\hline & $p=0.674$ & $p=0.134$ & $p=0.074^{*}$ & $p=0.503$ \\
\hline \multicolumn{5}{|l|}{ rs4588 CA } \\
\hline $\mathrm{CC}$ & $27.3,25.8-29.1(10)$ & $34.7,32.8-36.3(8)$ & $36.0 \pm 16.4(8)$ & $27.1,24.4-30.8(5)$ \\
\hline $\mathrm{CA}$ & $27.8,24.4-31.6(78)$ & $29.4,26.0-34.2(57)$ & $39.2 \pm 12.6(55)$ & $27.7,23.1-33.7(50)$ \\
\hline \multirow[t]{2}{*}{ AA } & $28.5,25.2-32.6(116$ & $28.4,23.7-33.5(122)$ & $45.3 \pm 13.0(93)$ & $28.2,22.7-37.6(89)$ \\
\hline & $p=0.680$ & $p=0.034$ & $p=0.009^{*}$ & $p=0.747$ \\
\hline \multicolumn{5}{|l|}{ rs7041 GT } \\
\hline GG & $28.6,24.7-33.0(44$ & 31.6,27.1-35.4 (41) & $38.7 \pm 13.3(33)$ & $28.0,23.2-35.9(31)$ \\
\hline GT & $28.3,24.8-31.2(103)$ & $30.0,24.5-36.3(86)$ & $43.7 \pm 12.9(80)$ & $28.6,22.7-35.0(70)$ \\
\hline \multirow[t]{2}{*}{$\mathrm{TT}$} & $27.1,24.8-31.9(57)$ & $26.3,22.4-31.2(59)$ & $43.9 \pm 14.2(43)$ & $27.9,22.7-38.3(42)$ \\
\hline & $p=0.797$ & $p=0.003$ & $p=0.150^{*}$ & $p=0.981$ \\
\hline \multicolumn{5}{|l|}{ rs2298849 TC } \\
\hline TT & $29.7,27.7-32.8(29)$ & $30.5,24.8-34.7(29)$ & $41.8 \pm 11.3(10)$ & $29.3,22.1-44.5(6)$ \\
\hline $\mathrm{TC}$ & $27.9,24.7-32.7(100)$ & $28.0,24.1-33.3(75)$ & $43.9 \pm 13.8(77)$ & $26.3,22.6-35.9(65)$ \\
\hline \multirow[t]{2}{*}{$\mathrm{CC}$} & $27.0,24.0-30.7(72)$ & $30.3,24.8-34.4(83)$ & $41.4 \pm 13.3(68)$ & $28.1,23.1-35.0(74)$ \\
\hline & $p=0.127$ & $p=0.303$ & $p=0.538^{*}$ & $p=0.910$ \\
\hline
\end{tabular}

Numbers in brackets represent numbers of test samples (i.e., numbers of study subjects).

Statistical tests: $\left(^{*}\right)$ one-way analysis of variance (mean $\left.\pm \mathrm{SD}\right)$. The remaining datasets were analyzed by the Kruskal-Wallis one-way analysis of variance on ranks test. Numerical values represent the median and $25-75 \%$ percentile range. 
Figure 1.
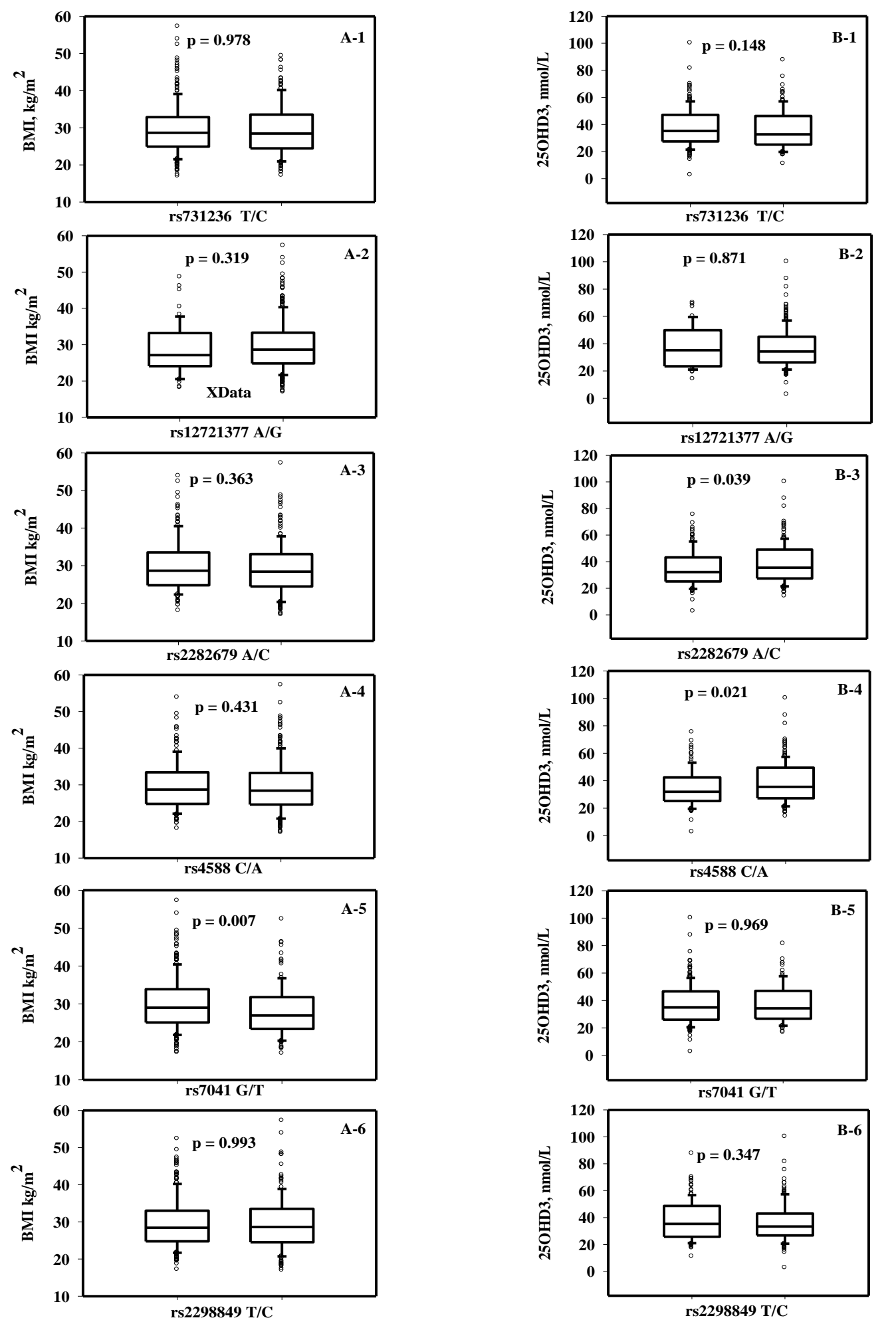
Figure 2A

\begin{tabular}{|l|l|l|l|l|l|}
\hline rs731236 T/C & rs-12721377 A/G & rs2282679 A/C & rs4588 C/A & rs7041 G/T & rs2298849 T/C \\
\hline
\end{tabular}

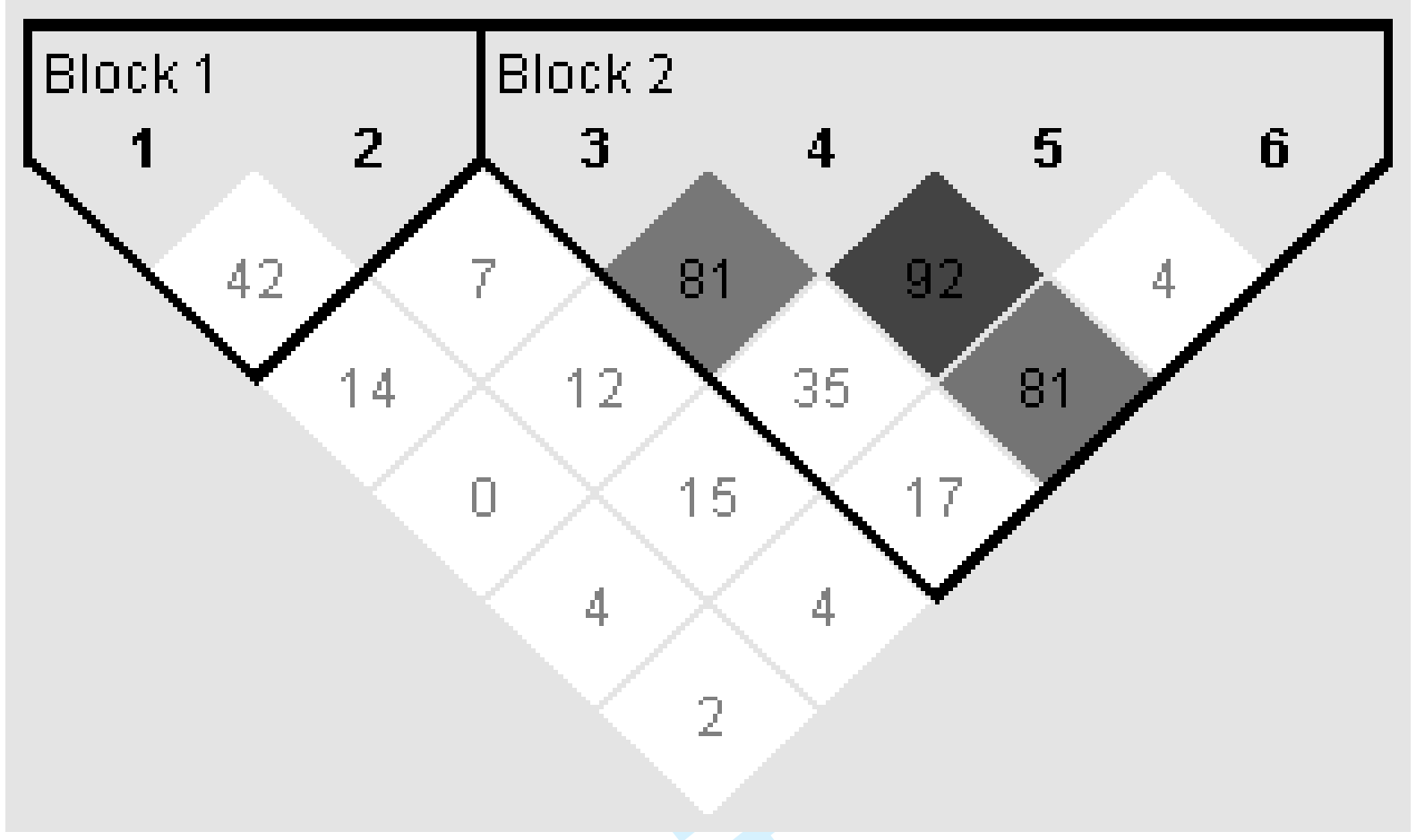

(2B)

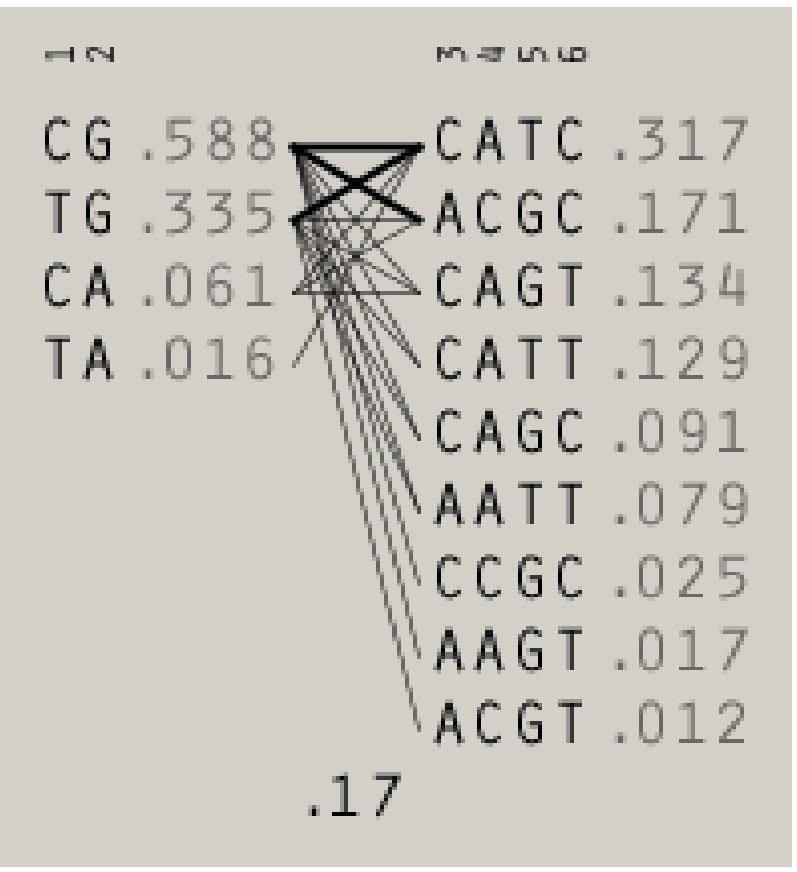

